\title{
Central and/or peripheral immunoreactivity of orexin-A in pregnant rats and women
}

\author{
G Sun, Z Tian'1, Y Yao, $\mathrm{H}$ Li and T Higuchi ${ }^{2}$ \\ Clinical Immunological Center, Affiliated Hospital of Qingdao Medical College, Qingdao University, Qingdao 266003, China \\ ${ }^{1}$ Department of Internal Medicine, Affiliated Hospital of Qingdao Medical College, Qingdao University, Qingdao 266003, China \\ ${ }^{2}$ Department of Physiology, Faculty of Medicine, University of Fukui, Fukui 910-1193, Japan \\ (Requests for offprints should be addressed to G Sun; Email: sungr@ qdumh.qd.sd.cn)
}

\begin{abstract}
Orexins ( $A$ and $B$ ) have been implicated in feeding behavior, energy balance and state of vigilance. During pregnancy, their involvement in feeding regulation and reproduction are poorly understood. In this study, we investigated orexin-A immunoreactivity in the hypothalamus and serum in pregnant rats and women by immunofluorescence staining, image analysis and radioimmunoassay, examined the correlation of serum orexin-A and leptin with gestational age in pregnant women by regression analysis, and explored the effect of leptin injected intracerebroventricularly (i.c.v.) on orexin-A immunoreactivity in the hypothalamus of normal rats by immunohistochemistry. The results showed that pregnant rats had significantly greater daily food intake on days 15 and 20 of pregnancy than virgin ones $(+27 \cdot 3 \%$, $P<0.01$ and $+38.6 \%, P<0.001$ respectively), with significantly fewer number and lower mean staining intensity of orexin-A-immunoreactive (ir) neurons on days 16 (both $P<0.05$ ) and 21 (both $P<0.01$ ) of pregnancy. Moreover, serum levels of orexin-A exhibited 2.0-fold and 2.2-fold increases (both $P<0.001$ ) in rats on days 16 and 21 of pregnancy compared with those in virgin rats, and 1.9-fold and 2.0-fold increases (both $P<0.001)$ in mid (13-26 weeks) and late pregnant women (27-40 weeks) compared with those in non-pregnant women. Simultaneously, serum levels of leptin showed a 2-3-fold and 2-2-fold increase (both $P<0.001$ ) in rats on days 16 and 21 of pregnancy, and a 3.3-fold and 4.3-fold increase (both $P<0.001$ ) in mid and late pregnant women. Serum levels of both orexin-A and leptin correlated positively with gestational age in pregnant women. Leptin injected i.c.v. significantly decreased the number $(P<0.01)$ and mean staining intensity $(P<0.01)$ of orexin-A-ir neurons in the hypothalamus, food intake $(P<0.01)$ and body weight gain $(P<0.001)$ compared with vehicle injection in normal rats. These results suggested that central and serum orexin-A might be involved in the regulation of feeding and energy metabolism during pregnancy. The change in central orexin-A immunoreactivity might be related to the increased serum leptin concentrations.
\end{abstract}

Journal of Molecular Endocrinology (2006) 36, 131-138

\section{Introduction}

The hypothalamus is an important integrating center of feeding and energy homeostasis. The lateral hypothalamic area (LHA) has long been considered as a feeding center (Bernardis \& Bellinger 1996). Orexins (A and B) are a novel family of peptides that were mainly discovered and characterized in the neurons located in the LHA. Orexin-A and orexin-B injected intracerebroventricularly (i.c.v.), even injected into the LHA at low doses, stimulate feeding (Sakurai et al. 1998, Edwards et al. 1999). Orexin-A is more potent than orexin-B in promoting feeding (Dube et al. 1999). Orexins and their receptors (orexin 1 R and $\operatorname{orexin}_{2} \mathrm{R}$ ) were initially identified in the brain (Sakurai 1999). Recent data have shown that many peripheral tissues express orexin receptors (orexin $1 \mathrm{R}$ and $\operatorname{orexin}_{2} \mathrm{R}$ ) (Johren et al. 2001) and there is detectable orexin-A in the circulation (Arihara et al. 2001). These data imply that circulating orexin-A may have some physiological actions, especially in the regulation of feeding and sleeping.

The mid and later stages of pregnancy are characterized by an increase in energy demand (Ota \& Yokoyama 1967). In lactating rats, we found a greater number and increased mean staining intensity of orexin-A-immunoreactive (ir) neurons in the LHA, increased daily food intake and body weight gain, unchanged prepro-orexin mRNA expression in the hypothalamus and decreased serum leptin levels (Sun et al. 2003). Involvement of orexins in feeding and reproductive function during pregnancy is not clear. Therefore, the purpose of this study was to evaluate the changes in orexin-A immunoreactivity in the hypothalamus and peripheral circulation in pregnant rats and women by immunofluorescence staining, image analysis and radioimmunoassay methods, and to explore the effects of an i.c.v. injection of leptin on orexin-A immunoreactive neurons in the hypothalamus of rats. 


\section{Materials and methods}

\section{Subjects and handling}

Ten-week-old female Wistar rats weighing 220-250 g, and adult male Wistar rats weighing 280-320 g, were purchased from Charles-River (Yokohama, Japan) and housed individually in an air-conditioned room $\left(23 \pm 2{ }^{\circ} \mathrm{C}\right)$ under a $12 \mathrm{~h}$ light/darkness cycle (lights on from 0600 to $1800 \mathrm{~h}$ ). Standard rat chow and tap water were available ad libitum throughout the experiment. After one week of adaptation, estrous cycles of female rats were determined by daily vaginal smears. On the third proestrous day of the observed estrous cycle, ten rats were mated with conspecific male rats and the mating day was considered as day 0 of pregnancy. Mated rats were divided into two groups, pregnancy I and pregnancy II, which were killed on days 16 and 21 of pregnancy respectively for orexin-A immunohistochemistry (Sun et al. 2003). Briefly, rats were anesthetized with sodium pentobarbital $(50 \mathrm{mg} / \mathrm{kg}$, i.p.) between 0900 and $1000 \mathrm{~h}$, punctured through angular vein with a hepavinized glass capillary for the collection of blood samples, and then perfused with $150 \mathrm{ml} 0 \cdot 1 \mathrm{M}$ phosphate buffer $\left(\mathrm{PB}, \mathrm{pH} 7 \cdot 4,4{ }^{\circ} \mathrm{C}\right.$ ) and $500 \mathrm{ml}$ Zamboni's solution successively. The brains were removed quickly, immersed in the same fixative $\left(4{ }^{\circ} \mathrm{C}\right)$ for $24 \mathrm{~h}$ with gentle shaking and cryoprotected in $20 \%$ and $30 \%$ sucrose in $0 \cdot 1 \mathrm{M} \mathrm{PB}\left(\mathrm{pH} 7 \cdot 4,4^{\circ} \mathrm{C}\right)$ for $24 \mathrm{~h}$ respectively. After brain dissection, the pregnancy was confirmed by checking the uterus of each pregnant rat. Another five control rats, diestrum virgin rats, were treated in the same way as the pregnant rats. In the clinical experiment, 20 healthy non-pregnant and 53 normal pregnant women were recruited as control and experimental groups respectively, who were admitted to the Affiliated Hospital of the Medical College, Qingdao University from October 2003 to March 2004. The pregnant women had not suffered from any complications of pregnancy, such as pregnancy-induced hypertension, obesity (body mass index $>25 \mathrm{~kg} / \mathrm{m}^{2}$ ), diabetes, anemia etc, and did not undergo any drug administration during pregnancy. They were divided into three groups: early $(n=18$, aged $28 \cdot 3 \pm 2 \cdot 9$ years, $<12$ weeks pregnant), mid ( $n=18$, aged $28 \cdot 3 \pm 4 \cdot 5,13-26$ weeks pregnant) and late $(n=17$, aged $30 \cdot 2 \pm 3.8$ years, 27 40 weeks pregnant) pregnancy according to their gestational weeks. None of the subjects had any remarkable past history. This protocol was approved by the Associate Committee of the Affiliated Hospital of the Medical College in Qingdao University in China.

\section{Intracerebroventricular cannula placement and i.c.v. administration of leptin}

Adult male Wistar rats, weighing 280-300 g, were anesthetized with sodium pentobarbital $(45 \mathrm{mg} / \mathrm{kg}$, i.p.) and placed in a stereotaxic frame. A 28-gauge stainless steel cannula was implanted into the right lateral cerebral ventricle. The coordinates of the guide cannula tip were identified from an atlas of the rat brain (Paxinos \& Watson 1986), $0.8 \mathrm{~mm}$ posterior to the bregma, $1.6 \mathrm{~mm}$ lateral to the midsagittal line and $4.3-4.5 \mathrm{~mm}$ ventral to the skull. After surgery, the cannula was fixed to the skull with four jeweler's screws and dental cement. A stainless steel plug was inserted into each cannula to prevent leakage of cerebral spinal fluid. The rats were allowed to recover for 7 days, and randomly subdivided into control and leptin groups ( $n=5$ /group). They were injected intracerebroventricularly with either $3 \mu \mathrm{l}$ vehicle (phosphate buffered saline, PBS) or recombinant murine leptin $(1 \mu \mathrm{g} / \mu \mathrm{l}$; Prepro Tech EG Ltd, London, UK) dissolved in PBS at the beginning of the night phase (1800 h). Daily food intake and body weight gain were monitored for three days (from 1800 to $1800 \mathrm{~h}$ ). On day 4 post injection, the same injections were repeated in the corresponding rats at $1800 \mathrm{~h}$. The next morning (0900-1000 h), the rats were killed for immunohistochemistry of orexin-A (Sun et al. 2003).

\section{Central orexin-A immunoreactivity}

The cryoprotected brains were quickly frozen in embedding solution with O.C.T. compound (Sakura Finetechnical Co. Ltd, Tokyo, Japan) in a cryostat (Leica CM1510, Nussloch, Germany). For pregnant rats, the brains were cut into $25 \mu \mathrm{m}$-thick coronal sections on the cryostat, collected in eight series (each series containing one eighth of all sections). One series of sections from each rat ranging from bregma $-2.4 \mathrm{~mm}$ to bregma $-3.6 \mathrm{~mm}$ was processed by immunofluorescence staining for orexin-A immunoreactivity. Briefly, sections were incubated in rabbit anti-orexin-A serum (1:2000; Peninsula Laboratories, San Carlos, CA, USA) in 0.01 M PBS (pH 7.4) with $0 \cdot 1 \%$ Triton-X 100 for $48 \mathrm{~h}$ at $4{ }^{\circ} \mathrm{C}$, which is specific to orexin-A of human, mouse and rat. Thereafter, the sections were thoroughly rinsed in $0.01 \mathrm{M}$ PBS and incubated with FITC-labeled anti-rabbit IgG antiserum (1:1000; Vector Laboratories, Burlingame, CA, USA) containing $2 \%$ normal rat serum for $1 \mathrm{~h}$ at room temperature. Sections were rinsed again in $0.01 \mathrm{M}$ PBS, mounted with glycerine solution. The negative controls were processed by omission of primary antiserum. For rats treated with i.c.v. injected leptin or vehicle, the brain sections were processed for orexin-A immunoreactivity by immunohistochemistry methods described previously (Sun et al. 2003) rather than by immunofluorescence staining.

\section{Quantitative analysis of immunoreactivity of orexin-A in the hypothalamus}

Orexin-A immunoreactivity in each section processed by immunofluorescence staining was observed with a 
fluorescence microscope (AX80T, Olympus, Tokyo, Japan). The microscopic images $(\times 40)$ enclosing the population of orexin-A-ir neurons in the unilateral hypothalamic area on one section were taken using a digital camera (Olympus DP50, Tokyo, Japan) attached to the fluorescence microscope using Viewfinder Life software (version 1.0; Olympus Corporation, Tokyo, Japan) under the same parameters and conditions for each section. The size of images was $1392 \times 1040$ pixels. For one section, two images including the left and right hypothalamic area were taken. The MacSCOPE program (version 2.59; Mitani, Fukui, Japan) can give each pixel a gray level numbering between 0 and 255, representing pure black (full light absorption) and pure white (full light transmission) respectively. The mean staining intensity of orexin-A-ir neurons in each image was expressed as mean gray level (Weaver \& Au 1997) by the MacSCOPE program. Neuronal counts were made for orexin-A-labeled neurons from each image according to the counting methods of MacSCOPE. Five sections (ten images) per rat, collected in every $200 \mu \mathrm{m}$ tissue from bregma $-2.6 \mathrm{~mm}$ to bregma $-3.4 \mathrm{~mm}$, were analyzed. The results were the mean of 10 images from five separate sections. In the leptin injection experiment, orexin-A immunoreactivity in each section processed by immunohistochemistry was observed with a Vanox-S microscope (AH-2, Olympus, Tokyo, Japan) as previously described (Sun et al. 2003). The microscopic images $(40 \times)$ of stained sections were transported to a video monitor using a digital camera (HC-2500 3 CCD, Fujix, Tokyo, Japan) attached to a Vanox-S microscope using Fujifilm/Photograb-2500 software (version 1.1; Fuji Photo Film Co. Ltd, Tokyo, Japan). The number and mean staining intensity of orexin-A-ir neurons in each image were analyzed by the MacSCOPE program (version 2.56; Mitani Corp.) (Sun et al. 2003).

\section{Serum levels of orexin-A and leptin}

For rats, blood samples were collected in the morning (0900 $1000 \mathrm{~h}$ ) on days 16 and 21 of pregnancy. Serum were separated within two hours and stored at $-80^{\circ} \mathrm{C}$. For pregnant and control women, blood samples were taken from the antecubital vein in the morning between 0730 and $0830 \mathrm{~h}$ after an overnight fast. Blood samples were centrifuged at $1500 \boldsymbol{g}$ for $15 \mathrm{~min}$. Serum samples were frozen and stored at $-80{ }^{\circ} \mathrm{C}$. Serum orexin-A levels were measured with a commercially available RIA kit (Phoenix Pharmaceuticals, Inc., Belmont, CA, USA), which is suitable for the determination of orexin-A of mouse, rat and human in serum, plasma and tissue. Serum leptin concentrations were determined with two RIA kits (Linco Research Inc., St Charles, MO, USA). They are specific for rat leptin and human leptin respectively. Protocols for the assays followed the methods supplied by the providers. Serum orexin-A and

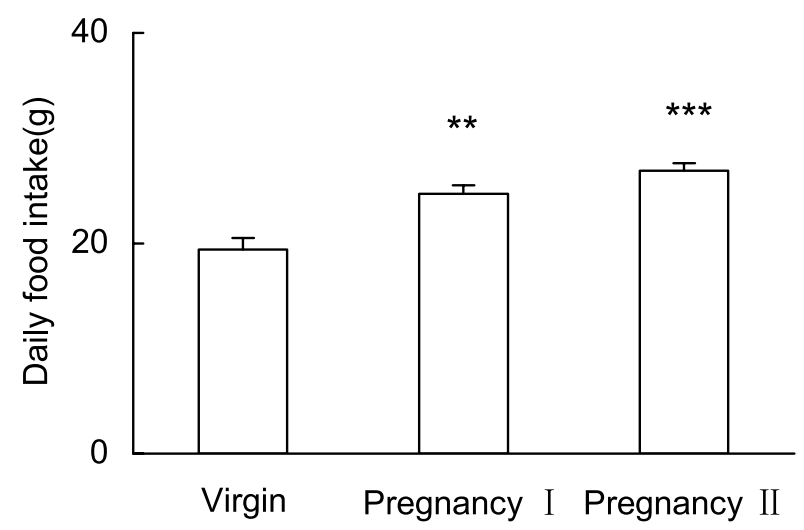

Figure 1 Daily food intake $(\mathrm{g})$ in virgin and pregnant rats on days 15 and 20 of pregnancy. ${ }^{* *} P<0.01,{ }^{* * *} P<0.001$ compared with virgin rats ( $n=5$ rats per group). Values are means \pm S.E.M.

leptin were assayed in duplicate, and expressed in terms of the orexin-A and leptin standards respectively. All the intra- and interassay levels were less than $8 \%$.

\section{Statistical analysis}

All data are given as the mean \pm S.E.M. Statistical significance of data was assessed by using one-way ANOVA followed by the Fisher's protected least significant difference test. In the leptin-treated experiment, data were analyzed by Student's $t$-test. $P<0 \cdot 05$ was regarded as a statistically significant difference.

\section{Results}

\section{Daily food intake in pregnant rats}

Daily food intake was monitored in groups of virgin control, pregnancy I (on day 15 of pregnancy) and pregnancy II (on day 20 of pregnancy) rats. As shown in Fig. 1, pregnant rats on days 15 and 20 of pregnancy had a significantly greater daily food intake than virgin control rats $(+27 \cdot 3 \%, P<0 \cdot 01$ and $+38 \cdot 6 \%, P<0 \cdot 001$ respectively).

\section{The number and staining intensity of orexin-A-ir neurons in the hypothalamus in pregnant rats}

The population of orexin-A-ir neurons in the unilateral hypothalamus of one section in groups of virgin control, pregnancy I (on day 16 of pregnancy) and pregnancy II (on day 21 of pregnancy) rats are shown in Fig. 2(A,B,C). The number of orexin-A-ir neurons was significantly decreased in rats on days $16(P<0.05$ vs virgin $)$ and 21 $(P<0.01$ vs virgin) of pregnancy (Fig. 2D). The mean staining intensity of orexin-A-ir neurons was also 

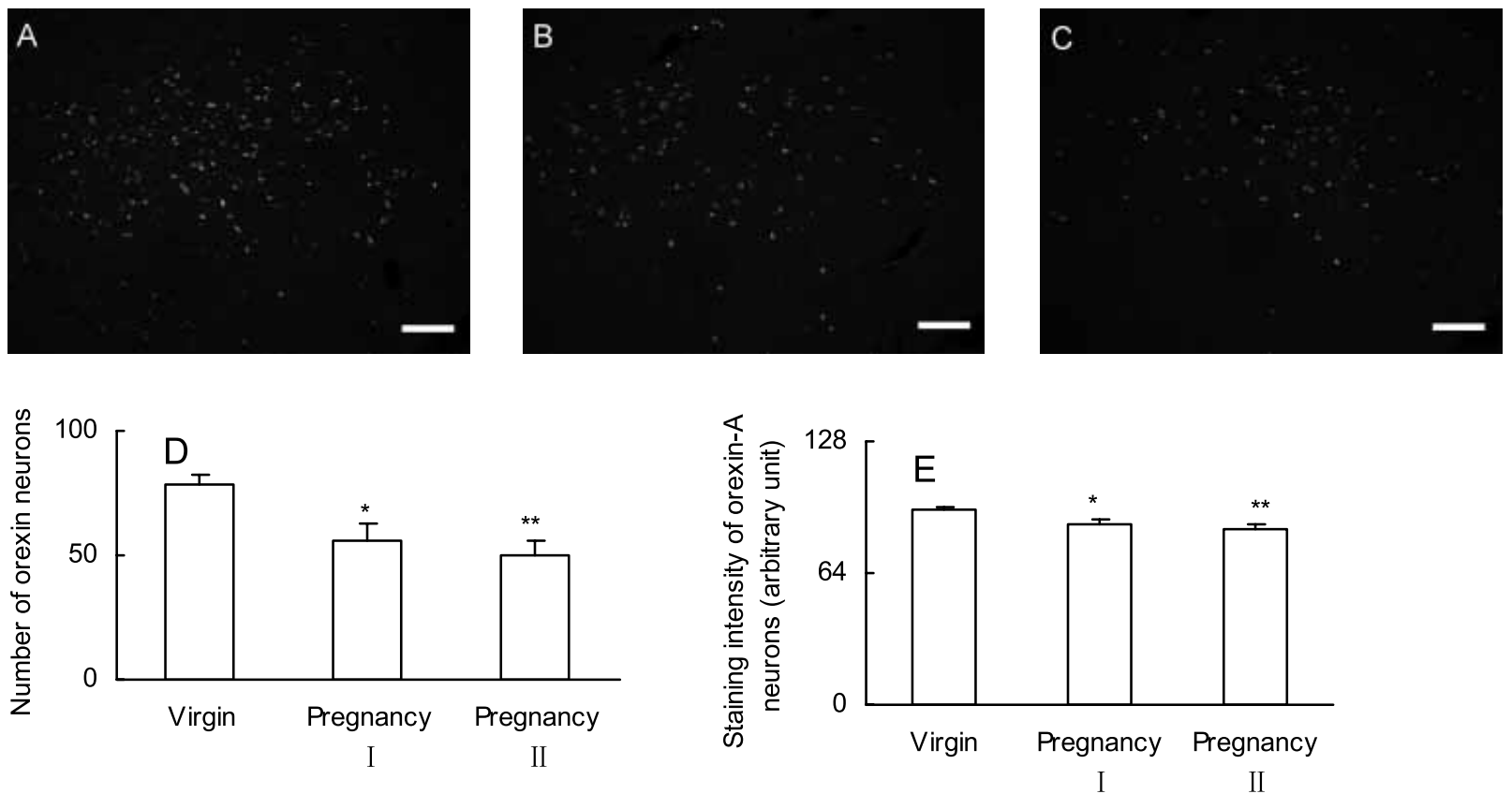

Figure 2 Orexin-A immunoreactive neurons in the unilateral hypothalamic region in a coronal section of brain in virgin (A) and in pregnant rats on day 16 (B) and day 21 (C) of pregnancy. Immunofluorescence staining; scale bars $=200 \mu \mathrm{m}$. The number (D) and staining intensity $(E)$ of orexin-A immunoreactive neurons in the unilateral hypothalamic region in rats on day 16 (Pregnancy I) and day 21 (Pregnancy II) of pregnancy are shown. ${ }^{*} P<0.05,{ }^{* *} P<0.01$ compared with virgin rats $(n=5$ rats per group). Values are means \pm S.E.M.

lowered in rats on days $16(P<0 \cdot 05$ vs virgin $)$ and 21 of pregnancy $(P<0.01$ vs virgin) (Fig. 2E).

\section{Serum levels of orexin-A and leptin in pregnant rats and women}

As shown in Fig. 3, serum orexin-A concentrations were significantly increased $2 \cdot 0$-fold and $2 \cdot 2$-fold (both $P<0 \cdot 001)$ in pregnancy I (on day 16 of pregnancy) and pregnancy II (on day 21 of pregnancy) groups respectively compared with virgin rats (Fig. 3A), and were significantly increased 1.9-fold and 2.0-fold (both $P<0.001)$ in mid and late pregnant women respectively (but not in early pregnant women) compared with non-pregnant women (Fig. 3B). Simultaneously, serum leptin concentrations showed a $2 \cdot 3$-fold and a 2.2-fold increase (both $P<0 \cdot 001$ ) in pregnancy I and II groups (Fig. 3G), and a 3.3-fold and 4.3-fold increase (both $P<0.001)$ in mid and late pregnant women but not in early-pregnant women (Fig. 3D).

\section{Correlation of serum levels of orexin-A and leptin with gestational age in women}

The result of regression analysis showed that serum levels of orexin-A $(r=0 \cdot 72, P<0 \cdot 001$; Fig. 4A) and leptin $(r=0 \cdot 85, P<0 \cdot 001$; Fig. 4B) correlated positively with gestational age in pregnant women.

\section{Effects of i.c.v. injection of leptin on food intake, body weight gain and immunoreactivity of orexin-A in the hypothalamus in normal rats}

As summarized in Table 1, daily food intake and body weight gain were significantly decreased $(P<0.01$ and $P<0.001$ respectively) by i.c.v. injection of leptin in normal rats on day 1 but not on days 2 to 3 post injections. Orexin-A-ir neurons in the unilateral hypothalamus in vehicle- and leptin-treated normal rats are shown in Fig. 5(A,B). The number and mean staining intensity of orexin-A-ir neurons were significantly decreased by i.c.v. injection of leptin in normal rats (Fig. 5C, $P<0 \cdot 01$; Fig. 5D, $P<0.01$ ).

\section{Discussion}

In the present study, we observed that rats had significantly greater daily food intake on days 15 and 20 of pregnancy, decreased number and staining intensity of orexin-A-ir neurons on days 16 and 21 of pregnancy, and increased serum levels of orexin-A and leptin on 

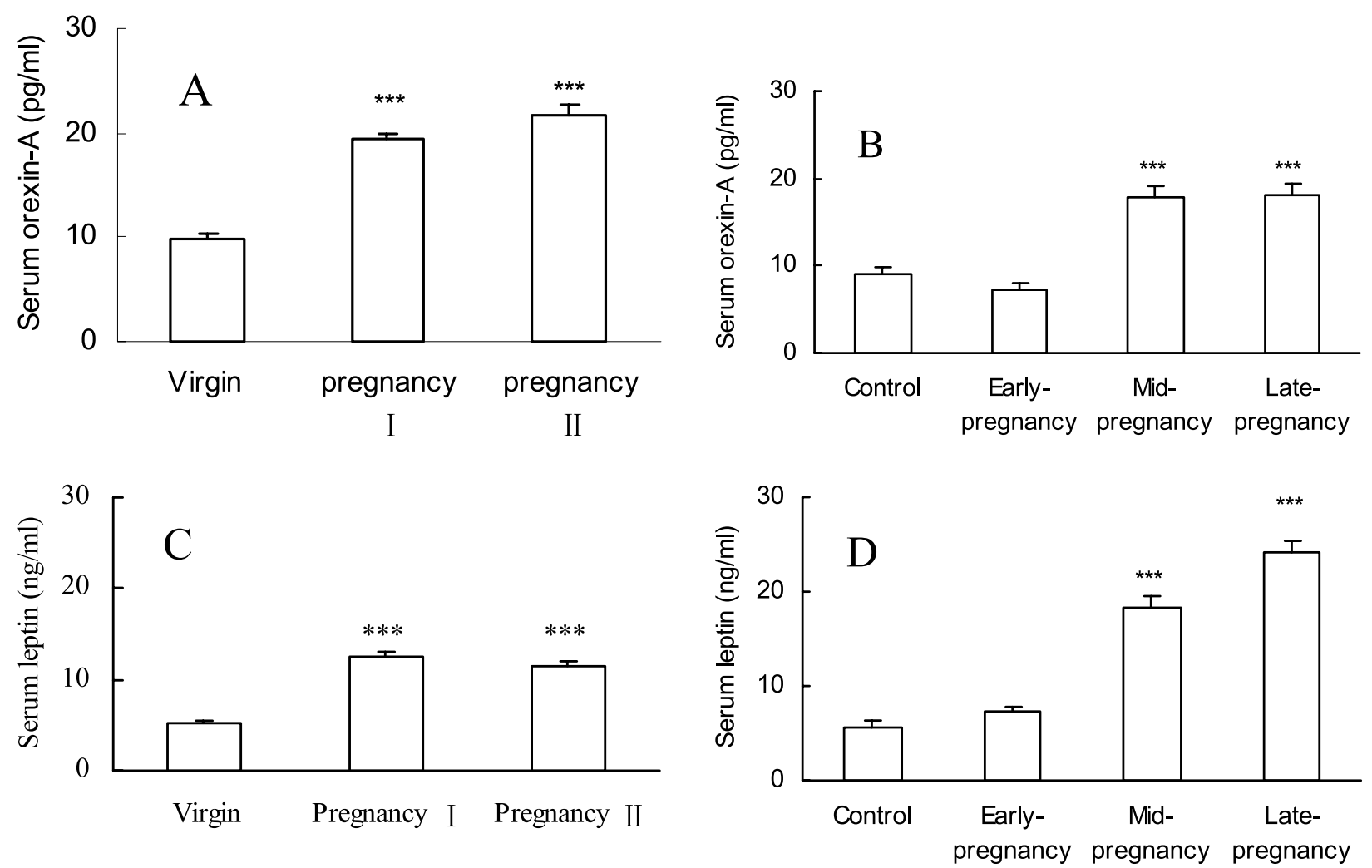

Figure $3(A, B)$ Serum orexin-A concentrations in rats on day 16 (Pregnancy I) and day 21 (Pregnancy II) of pregnancy $(n=5$ rats per group) (A) and in early, mid and late pregnant women (B). (C, D) Serum leptin concentrations in rats on day 16 (Pregnancy I) and day 21 (Pregnancy II) of pregnancy (C) and in early, mid and late pregnant women (D). ${ }^{\star \star} P<0 \cdot 01,{ }^{\star \star \star} P<0 \cdot 001$ compared with virgin rats or non-pregnant women. Values are means \pm S.E.M.

days 16 and 21 of pregnancy compared with virgin rats. In clinical experiments, pregnant women in mid and late pregnancy exhibited significantly higher serum levels of
orexin-A and leptin than non-pregnant women. Serum levels of orexin-A and leptin in pregnant women correlated positively with gestational age. To our
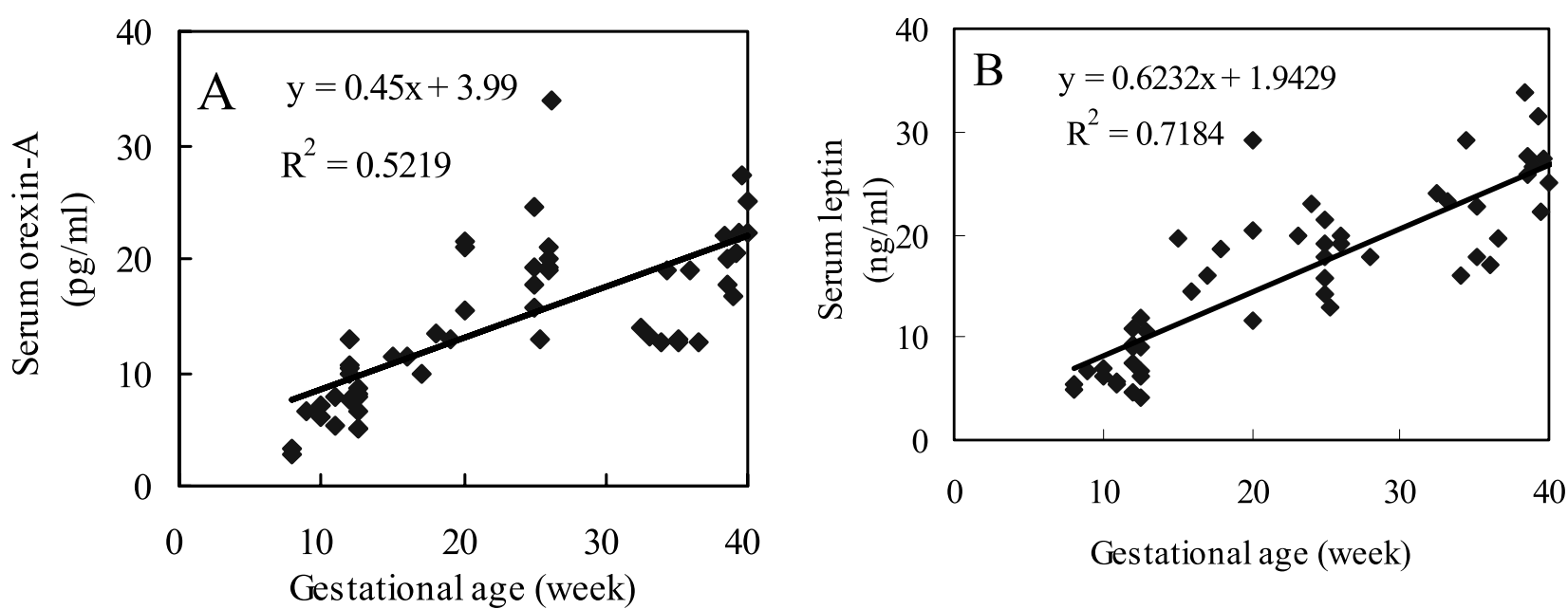

Figure 4 Correlations of serum concentrations of orexin-A (A) and leptin (B) with gestational age in women ( $n=53)$. Values are means \pm S.E.M. 
Table 1 Effect of i.c.v. leptin administration (3 $\mathrm{gg} / \mathrm{rat})$ on daily food intake and body weight gain in normal rats. Values are means \pm S.E.M ( $n=5$ rats/group)

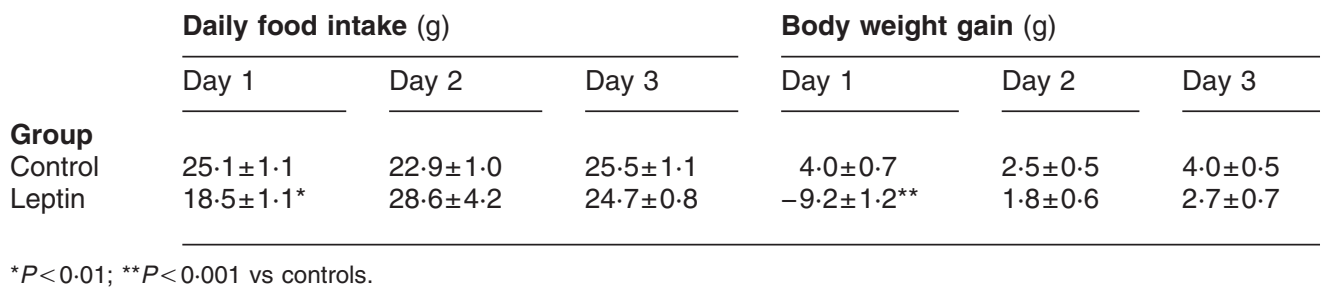

knowledge, the current data represent the first demonstration of the changes in orexin-A immunoreactivity in the hypothalamus and circulation of pregnant rats and women. Some data indicated that preproorexin mRNA expression during late pregnancy was lower than that on day 1 post partum in rats (Wang et al.
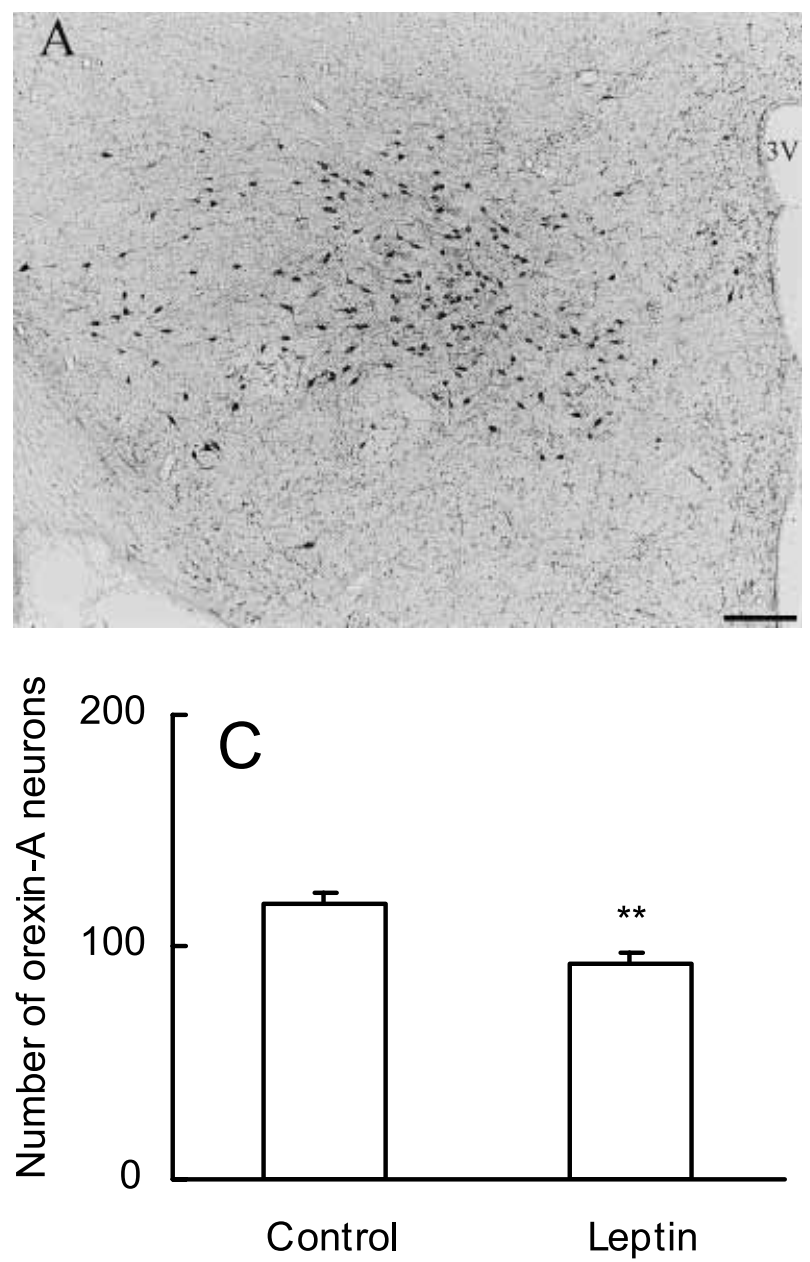

2003). But Wang et al. did not study the difference in prepro-orexin mRNA expression in virgin and pregnant rats, and did not observe orexin-A immunoreactivity in their study. Previous studies on prepro-orexin mRNA expression during pregnancy are confusing, indicating opposite results. One group (Garcia et al. 2003) reported
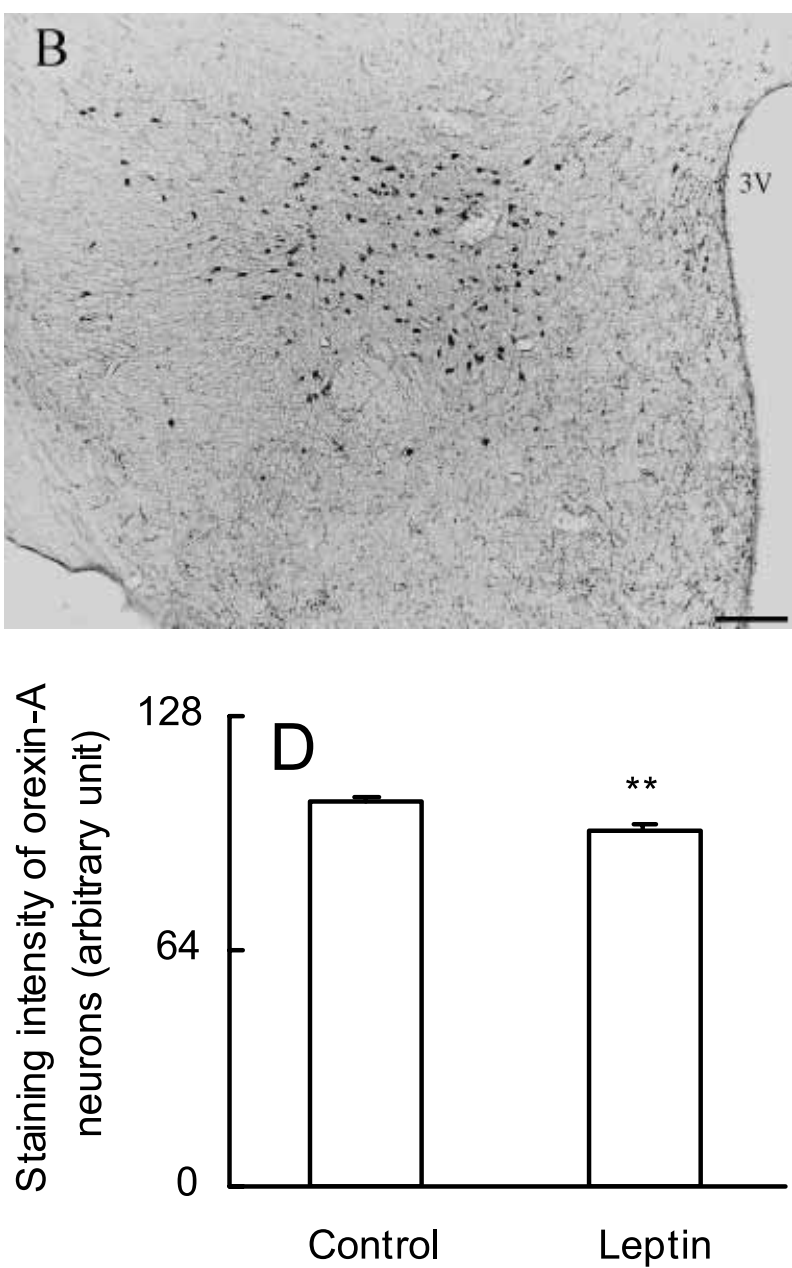

Figure 5 (A, B) Orexin-A immunoreactive neurons in the unilateral hypothalamus region (coronal section) of brain in i.c.v. vehicle-injected $(A)$ and leptin-injected $(B)$ normal rats. Immunohistochemistry staining; scale bars $=200 \mu \mathrm{m}$. (C, D) The effects of i.c.v. administration of leptin on number (C) and staining intensity (D) of orexin-A immunoreactive neurons/unilateral hypothalamic region in normal rats. ${ }^{* \star} P<0.01$ compared with control rats $(n=5$ rats per group). Values are means \pm S.E.M. 
decreased, while another group (Kanenishi et al. 2004) reported increased levels of prepro-orexin mRNA in the rat brain. Perhaps this discrepancy can be explained by the different methods used in the experiments. Our results indicate decreased levels of orexin-A immunoreactivity in the hypothalamus during pregnancy, which is in line with the observations of Garcia et al. However, orexin-A immunoreactivity in the hypothalamus during pregnancy is opposite to our previous observations during lactation (Sun et al. 2003), indicating that hypothalamic orexin-A may have different roles in the hyperphagia induced by pregnancy and lactation.

A regulatory role of leptin on orexin neurons has been speculated (Beck \& Richy 1999, Lopez et al. 2000). Food deprivation decreased serum leptin concentrations and increased serum levels of orexin-A (Li et al. 1998, Komaki et al. 2001) and hypothalamic prepro-orexin mRNA expression (Mondal et al. 1999). The effect of food deprivation on prepro-orexin mRNA can be reversed by exogenous leptin administration (Lopez et al. 2000) and chronic treatment with leptin for 7 days significantly decreased orexin-A concentration in the LHA (Beck \& Richy 1999). Orexin neurons in the LHA express leptin receptors (Hakansson et al. 1999). In addition, leptin inhibited the increase in intracellular calcium ion concentration $\left(\left[\mathrm{Ca}^{2+}\right] \mathrm{i}\right)$ induced by a reduction in the glucose concentration of glucosesensitive neurons in the arcuate nucleus and LHA via the leptin receptor expressed in these neurons (Funahashi et al. 1999). In this study, we observed that serum levels of leptin were increased in both pregnant rats and women, which is consistent with results previously reported (Johnstone \& Higuchi 2001). The total amount of leptin mRNA in maternal adipose tissues significantly increased as pregnancy advanced and reached about 2.5-fold that of non-pregnant rats on day 19 of pregnancy (Kawai et al. 1997). In this study, we observed that leptin injected by the i.c.v. route significantly decreased the number and mean staining intensity of orexin-A-ir neurons in the hypothalamus. Taken together, the increase in leptin levels may contribute to the decrease in hypothalamic orexin-A immunoreactivity in pregnant rats through the activation of specific leptin receptors located on orexin neurons. We have no clear explanation why serum levels of orexin A were increased while central orexin-A levels were decreased in pregnant rats. Serum orexin-A might have other origins, such as the gut and pancreas. In addition, circulating orexin-A and leptin levels change inversely in relation to each other in fasting non-obese humans (Komaki et al. 2001) while in this study, they changed in parallel, indicating that the involvement of circulating orexin-A and leptin in pregnant rats and women differed from that in the fasting state. In addition, some (25\%) LHA neurons are thought to be glucose-sensitive (Oomura et al. 1974, Bernardis \&
Bellinger 1996). The activity of isolated orexin neurons is inhibited by glucose (Yamanaka et al. 2003), but it is difficult to explain the change in orexin-A immunoreactivity in terms of unchanged glucose levels in pregnant rats and women.

Recently, orexin-A has been implicated to play a role in reproduction. Immunoreactivity of orexin neurons changed during the estrous cycle in rats (Porkka-Heiskanen et al. 2004). Orexin-A or orexin-B administered intracerebroventricularly reduces serum luteinizing hormone (LH) levels and suppresses the pulsatile secretion of LH (Irahara et al. 2001, Kok et al. 2004), indicating an involvement of orexins in the regulation of reproductive endocrine functions. Coadministration of i.c.v. orexin-A and intravenous naloxone (a specific opioid antagonist) significantly restored the mean LH concentration and the pulse frequency, implying that orexin-A suppresses gonadotropinreleasing hormone secretion via beta-endorphin. These data suggest that the inhibition of the hypothalamicpituitary-ovarian axis during pregnancy may be related to the increase in orexin-A levels in the circulation.

In conclusion, we provide evidence that central and peripheral orexin-A immunoreactivities were down- and up-regulated respectively in pregnant rats. The change in circulating levels of orexin-A and leptin was consistent in pregnant women and rats. Serum levels of orexin-A and leptin correlated positively with gestational age in pregnant women. The central and peripheral changes in orexin-A might be involved in the feeding, sleeping, and energy balance in pregnant rats and women. The increase in circulating leptin during pregnancy might inhibit central orexin-A expression. The interaction and relationship between central and circulating orexin-A still remains unclear.

\section{Acknowledgements}

Part of these studies was supported by a grant from the Ministry of Education of the People's Republic of China (no. 2004-527). We thank Dr AJ Douglas for her helpful suggestions in designing the experiment. The technical assistance of Drs T Murata, K Narita and Mr $\mathrm{T}$ Usami is greatly appreciated. The authors declare that there is no conflict of interest that would prejudice the impartiality of this scientific work.

\section{References}

Arihara Z, Takahashi K, Murakami O, Totsune K, Sone M, Satoh F, Ito S \& Mouri T 2001 Immunoreactive orexin-A in human plasma. Peptides 22 139-142.

Beck B \& Richy S 1999 Hypothalamic hypocretin/orexin and neuropeptide $\mathrm{Y}$ : divergent interaction with energy depletion and leptin. Biochemical and Biophysical Research Communications 258 $119-122$. 
Bernardis LL \& Bellinger LL 1996 The lateral hypothalamic area revisited: ingestive behavior. Neuroscience Biobehaviour Reviews 20 189-287.

Dube MG, Kalra SP \& Kalra PS 1999 Food intake elicited by central administration of orexins/hypocretins: identification of hypothalamic sites of action. Brain Research 842 473-477.

Edwards CM, Abusnana S, Sunter D, Murphy KG, Ghatei MA \& Bloom SR 1999 The effect of the orexins on food intake: comparison with neuropeptide $\mathrm{Y}$, melanin-concentrating hormone and galanin. Fournal of Endocrinology 160 R7-R12.

Funahashi H, Yada T, Muroya S, Takigawa M, Ryushi T, Horie S, Nakai Y \& Shioda S 1999 The effect of leptin on feeding-regulating neurons in the rat hypothalamus. Neuroscience Letters 264 117-120.

Garcia MC, Lopez M, Gualillo O, Seoane LM, Dieguez C \& Senaris RM 2003 Hypothalamic levels of NPY, MCH, and prepro-orexin mRNA during pregnancy and lactation in the rat: role of prolactin. FASEB Foumal 17 1392-1400.

Hakansson M, de Lecea L, Sutcliffe JG, Yanagisawa M \& Meister B 1999 Leptin receptor- and STAT3-immunoreactivities in hypocretin/orexin neurones of the lateral hypothalamus. Fournal of Neuroendocrinology 11 653-663.

Irahara M, Tamura T, Matuzaki T, Saito S, Yasui T, Yamano S, Kamada M \& Aono T 2001 Orexin-A suppresses the pulsatile secretion of luteinizing hormone via beta-endorphin. Biochemical and Biophysical Research Communications 281 232-236.

Johnstone LE \& Higuchi T 2001 Food intake and leptin during pregnancy and lactation. Progress in Brain Research 133 215-227.

Johren O, Neidert SJ, Kummer M, Dendorfer A \& Dominiak P 2001 Prepro-orexin and orexin receptor mRNAs are differentially expressed in peripheral tissues of male and female rats. Endocrinology 142 3324-3331.

Kanenishi K, Ueno M, Momose S, Kuwabara H, Tanaka H, Sato C, Kobayashi T, Hino O, Sakamoto H \& Hata T 2004 Prepro-orexin mRNA expression in the rat brain is increased during pregnancy. Neuroscience Letters 368 73-77.

Kawai M, Yamaguchi M, Murakami T, Shima K, Murata Y \& Kishi K 1997 The placenta is not the main source of leptin production in pregnant rat: gestational profile of leptin in plasma and adipose tissues. Biochemical and Biophysical Research Communications 240 798-802.

Kok SW, Roelfsema F, Overeem S, Lammers GJ, Frolich M, Meinders AE \& Pijl H 2004 Pulsatile LH release is diminished, whereas FSH secretion is normal, in hypocretin-deficient narcoleptic men. American Fournal of Physiology, Endocrinology and Metabolism 287 E630-E636.

Komaki G, Matsumoto Y, Nishikata H, Kawai K, Nozaki T, Takii M, Sogawa H \& Kubo C 2001 Orexin-A and leptin change inversely in fasting non-obese subjects. European fournal of Endocrinology 144 645-651.
Li H, Matheny M, Tumer N \& Scarpace PJ 1998 Aging and fasting regulation of leptin and hypothalamic neuropeptide $\mathrm{Y}$ gene expression. American Fournal of Physiology 275 E405-E411.

Lopez M, Seoane L, Garcia MC, Lago F, Casanueva FF, Senaris R \& Dieguez C 2000 Leptin regulation of prepro-orexin and orexin receptor mRNA level in the hypothalamus. Biochemical and Biophysical Research Communications 269 41-45.

Mondal MS, Nakazato M, Date Y, Murakami N, Yanagisawa M \& Matsukura S 1999 Widespread distribution of orexin in rat brain and its regulation upon fasting. Biochemical and Biophysical Research Communications 256 495-499.

Oomura Y, Ooyama H, Sugimori M, Nakamura T \& Yamada Y 1974 Glucose inhibition of the glucose-sensitive neuron in the rat lateral hypothalamus. Nature 247 284-286.

Ota K \& Yokoyama A 1967 Body weight and food consumption of lactating rats: effects of ovariectomy and of arrest and resumption of suckling. Fournal of Endocrinology 38 251-261.

Paxinos G \& Watson C 1986 The Rat Brain in Stereotaxic Coordinates, edn 2. Tokyo: Academic Press.

Porkka-Heiskanen T, Kalinchuk A, Alanko L, Huhtaniemi I \& Stenberg D 2004 Orexin A and B levels in the hypothalamus of female rats: the effects of the estrous cycle and age. European Fournal of Endocrinology 150 737-742.

Sakurai T 1999 Orexins and orexin receptors: implication in feeding behavior. Regulatory Peptides 85 25-30.

Sakurai T, Amemiya A, Ishii M, Matsuzaki I, Chemelli RM, Tanaka H, Williams SC, Richarson JA, Kozlowski GP, Wilson S, Arch JR, Buckingham RE, Haynes AC, Carr SA, Annan RS, McNulty DE, Liu WS, Terrett JA, Elshourbagy NA, Bergsma DJ \& Yanagisawa M 1998 Orexins and orexin receptors: a family of hypothalamic neuropeptides and $\mathrm{G}$ protein-coupled receptors that regulate feeding behavior. Cell 92 573-585.

Sun G, Narita K, Murata T, Honda K \& Higuchi T 2003 Orexin-A immunoreactivity and prepro-orexin mRNA expression in hyperphagic rats induced by hypothalamic lesions and lactation. Journal of Neuroendocrinology 15 51-60.

Wang JB, Murata T, Narita K, Honda K \& Higuchi T 2003 Variation in the expression of orexin and orexin receptors in the rat hypothalamus during the estrous cycle, pregnancy, parturition, and lactation. Endocrine 22 127-134.

Weaver JR \& Au JL 1997 Comparative scoring by visual and image analysis of cells in human solid tumors labeled for proliferation markers. Cytometry 27 189-199.

Yamanaka A, Beuckmann CT, Willie JT, Hara J, Tsujino N, Mieda M, Tominaga M, Yagami K, Sugiyama F, Goto K, Yanagisawa M \& Sakurai T 2003 Hypothalamic orexin neurons regulate arousal according to energy balance in mice. Neuron 38 701-713.

Received in final form on 16 September 2005

Accepted on 3 November 2005

Made available online as an Accepted Preprint 1 December 2005 